\title{
Molecular changes to tendons after collagenase-induced acute tendon injury in a senescence-accelerated mouse model
}

Yasuhiro Ueda, Atsuyuki Inui, Yutaka Mifune*, Fumiaki Takase, Takeshi Kataoka, Takashi Kurosawa, Kohei Yamaura, Takeshi Kokubu and Ryosuke Kuroda

\begin{abstract}
Background: Aging impairs tendon healing and is a potential risk factor for chronic tendinitis. During normal aging, tendons undergo structural and biomechanical degenerative changes, accompanied by a reduction in the number of tenocytes and changes to their properties. However, molecular changes in aged tendons under inflammatory conditions are not well understood. The present study analyzed the molecular changes in collagenase induced acute tendon injury using a senescence-accelerated mouse (SAM) model.

Methods: SAMP6 mice were used as an aging animal model and SAMR1 mice were used as a control to represent a senescence-resistant inbred strain. All the mice used in the study were 40 weeks old. Collagenase I from Clostridium histolyticum $(20 \mu \mathrm{L})$ was injected percutaneously to the tendon-bone junction of the Achilles tendon. Two weeks after treatment, the Achilles tendons were harvested and stained using Picrosirius Red to determine collagen expression. Real-time PCR was performed to analyze gene expression of IL-6, tenomodulin, type I and type II collagen, MMP-9, TIMP-1, and TIMP-2.

Results: Collagenase injection resulted in significantly higher gene expression of IL-6 but significantly lower tenomodulin expression compared with the control in SAMP6 and SAMR1 mice. In SAMP6 mice, gene expression of type III collagen and MMP-9 was significantly higher in the collagenase-injected group compared with the control group. SAMP6 mice also showed lower expression of type I collagen, TIMP-1, and TIMP-2 in the collagenaseinjected group compared with the control group. Picrosirius Red staining showed the highest expression of type III collagen in the collagenase-injected SAMP6 group compared with the other groups.

Conclusions: The collagenase-injected SAMP6 group showed higher expression of IL-6, MMP-9, and type III collagen and lower expression of type I collagen, TIMP-1, and TIMP-2, which are known to suppress metalloproteinases. The results indicate that aging may lead to dysfunction of the tendon healing process after acute tendon injury.
\end{abstract}

Keywords: Aging, Acute tendon injury, Tendon degeneration

\footnotetext{
* Correspondence: m-ship@kf7.so-net.ne.jp

Department of Orthopaedic Surgery, Kobe University Graduate School of

Medicine, 7-5-1 Kusunoki-cho, chuo-ku, Kobe 650-0017, Japan
}

(c) The Author(s). 2019 Open Access This article is distributed under the terms of the Creative Commons Attribution 4.0 International License (http://creativecommons.org/licenses/by/4.0/), which permits unrestricted use, distribution, and reproduction in any medium, provided you give appropriate credit to the original author(s) and the source, provide a link to the Creative Commons license, and indicate if changes were made. The Creative Commons Public Domain Dedication waiver (http://creativecommons.org/publicdomain/zero/1.0/) applies to the data made available in this article, unless otherwise stated. 


\section{Background}

Aging is associated with impaired tendon healing and is a potential risk factor for chronic tendinitis, as suggested by the high prevalence of rotator cuff disorders in the elderly [1]. Aging has also been shown to be an important factor associated with the probability of re-tear [2]. During normal aging, tendons undergo structural and biomechanical degenerative changes, accompanied by a reduction in the number of tenocytes, as well as changes to their properties [3]. A recent increase in health awareness has seen an increase in the number of elderly people participating in sports; however, there is a potential risk of tendon injury or overuse, such as tendinitis, in this population. Although, there have been several reports on the molecular changes to tendons during normal aging, molecular changes in aged tendons under inflammatory conditions are not well understood. Matrix metalloproteinases (MMPs) and their inhibition by tissue inhibitor of metalloproteinases (TIMPs) influence the degree of degradation as well as the production and remodeling of the tendon extracellular matrix [4]. In aged tendon, compared with those of younger people, the normal level of MMP-2 and MMP - 9 are higher [5] and mechanical stress cause higher MMP activity [6]. Diminished collagen content and mRNA expression of type I and type III collagen have been reported in aged rat Achilles tendons [5]. To date, there have been no reports regarding MMP activity and collagen synthesis under inflammatory conditions in the aged tendon. In the present study, we used a senescence-accelerated mouse (SAM) model to analyze the molecular changes in collagenase induced acute tendon injury.

\section{Methods}

\section{Animal models}

All the animal procedures were performed under the approval and guidance of the Animal Care and Use Committee at our institution.As an aging animal model, we used senescence-accelerated mouse prone (SAMP) mice, which are a widely used aging muscle model. The SAM model has been developed at Kyoto University since 1970 through the selective inbreeding of the AKR/J strain of mice, donated by the Jackson Laboratory in 1968, based on a graded score for senescence, life span, and pathologic phenotype [7]. The SAM strain has a short life span and strain-specific pathological features and is an established experimental animal model for age-associated disease research in systematically designed studies [8]. As a control, we used SAMR (senescence-accelerated mouse resistant) mice to represent a senescence-resistant inbred strain. Among several SAM subtypes, SAMP6 is used as a murine model of senile osteoporosis as it has low bone mass in the vertebra, tibia, and femur [9]. Since the strain has been widely used in orthopedic research, the SAMP6 strain was used as an aged acute tendon injury model. In a 32 weeks old SAMP6 mouse, a reduction in the number of fibroblasts and the diameter of the tendon collagen fibers was reported [10]. We used 40-week-old SAMP6 and SAMR1 male mice $(n=24$ for each strain). The mean body weight of the SAMR1 and SAMP6 mice was $36.6 \pm 1.86(34.2-39.9) \mathrm{g}$ and $45.7 \pm 4.53$ (39.5-53.6) g, respectively. Male mice were used in this study since previous studies indicated estrogen levels in female mice play a crucial role in tendon metabolism and alter the production of various growth factors [11]. SAMP6 and SAMR1 mice were purchased from Japan SLC (Shizuoka, Japan). They were housed in standard laboratory conditions (12-h light:12-h dark cycle, room air temperature $22-24^{\circ} \mathrm{C}$, two mice per cage) and had free access to tap water and food pellets.

\section{Acute tendon injury model}

Twenty four SAMR1 mice and twenty four SAMP6 mice were used in the study. After anesthesia using isoflurane (Wako, Osaka, Japan), $0.3 \mathrm{mg}$ of collagenase I from Clostridium histolyticum (Sigma Aldrich, Ca., USA) was dissolved in $20 \mu \mathrm{L}$ of phosphate buffered saline and injected into the mid-portion of the left Achilles tendon of all mice using a 30 -gauge needle $[12,13]$. The contralateral limb was injected $20 \mu \mathrm{L}$ of phosphate buffered saline and used as a control. Free cage activity was allowed after injection. All the animals survived until they were sacrificed. At two weeks after injection, all mice were euthanized with an overdose of isoflurane (Wako, Osaka, Japan) and intraperitoneal injection of pentobarbital sodium (Kyoritsu Seiyaku, Tokyo, Japan). The Achilles tendon was harvested to analyze gene expression and histological evaluation.

\section{Quantitative real-time polymerase chain reaction (PCR)}

The Achilles tendons were carefully isolated from contaminating connective tissue and minced. Total RNA was extracted from the tendons using an RNeasy Mini Kit (Qiagen, Valencia, CA, USA) with homogenizer then reverse transcribed to produce single-stranded cDNA using a high-capacity cDNA reverse transcription kit (Applied Biosystems, Foster City, CA, USA). Real-time PCR was performed in duplicate with CDNA samples using a fast real-time PCR system and SYBR Green reagents to analyze mRNA expression of interleukin-6 (IL-6), tenomodulin, type III collagen, MMP-9, TIMP-1, and TIMP -2 . The results were normalized to mRNA levels of the housekeeping gene glyceraldehyde 3-phosphate dehydrogenase (GAPDH) and were expressed relative to their levels in normal culture levels using the $2^{(-\Delta \Delta \mathrm{CT})}$ method ( $n=16$ in each group).

The oligonucleotide primer sequences used for real-time PCR amplification were as follows: 
IL-6, 5' - TAGTCCTTCCTACCCCAATTTCC -3' (forward) and 5' - TTGGTCCTTAGCCACTCCTTC -3' (reverse); tenomodulin, 5' - TGTACTGGATCAATCCCAC TCT -3 ' (forward) and 5'-GCTCATTCTGGTCAATCCC CT -3' (reverse); type I collagen, 5-CCA GCG AAG AAC TCA TAC AGC-3' (forward) and 5' - GGA CAC CCC TTC TAC GTT GT-3' (reverse); type III collagen, $5^{\prime}$ - TG G AGA CAG GTC AGA CCT G-3' (forward) and 5'TAT TCG ATG ACT GTC TTG CC-3' (reverse); MM P-9, 5' - TGAATCAGCTGGCTTTTGTG -3' (forward) and 5' - ACCTTCCAGTAGGGGCAACT -3' (reverse); TIMP-1, 5' - GCAACTCGGACCTGGTCATAA $-3^{\prime}$ (forward) and 5' - CGGCCCGTGATGAGAAACT -3' (reverse); TIMP-2, 5' - TCAGAGCCAAAGCA GTGAGC -3' (forward) and 5' - GCCGTGTAGATAAA CTCGATGTC -3' (reverse); and GAPDH, 5'- GGT GGT CTC CTC TGA CTT CAA CA-3' (forward) and
5'- GTT GCT GTA GCC AAA TTC GTT GT-3' (reverse).

\section{Picrosirius red staining for collagen expression}

Picrosirius Red staining was performed to analyze the orientation of collagen fibers in the tendons. Frozen, long-axis sections of Achilles tendons embedded in Optimal Cutting Temperature (OCT) compound (Sakura Finetek USA, Inc., Torrance, CA, USA) were serially cut into 7- $\mu \mathrm{m}$-thick sections and fixed using $10 \%$ phosphatebuffered paraformaldehyde at room temperature for 15 min. Tissues processed for histology were stained using a Picrosirius Red staining kit (Polyscience, Inc. Warrington, PA) according to the manufacturer's instructions. A light microscope fitted with a light polarizer was used to capture the digital images. The organization of the Achilles tendon collagen fibers was visualized by turning the polarizer to
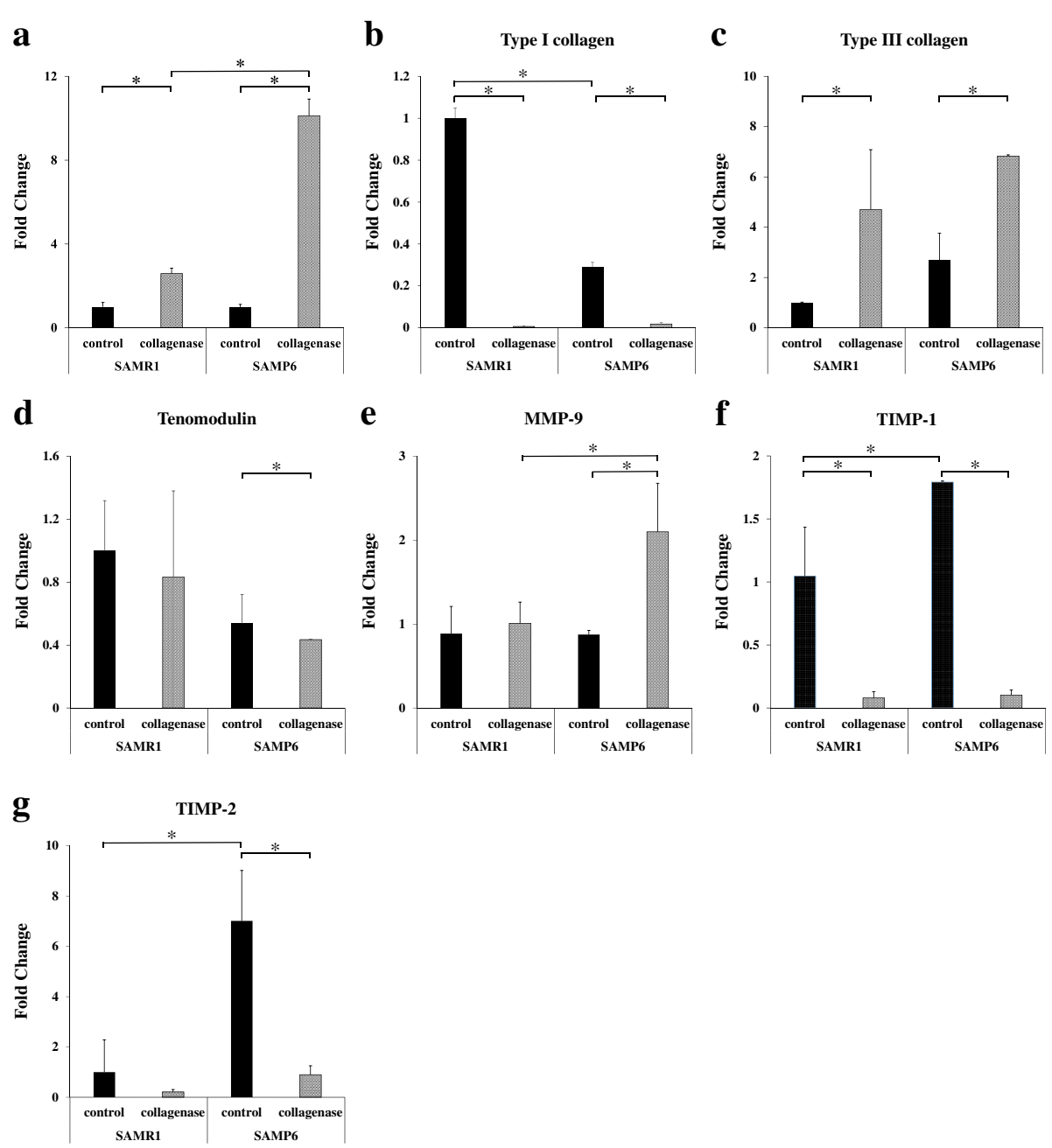

Fig. 1 mRNA expressions in the Achilles tendons of SAMR1 and SAMP6. a IL-6 is a marker for inflammation, b, $\mathbf{c}$ type I and type III collagen are markers for degeneration, and $\mathbf{d}, \mathbf{e}, \mathbf{f}, \mathbf{g}$ tenomodulin, MMP-9, TIMP-1, and TIMP-2 are markers for tendon remodeling. $\left({ }^{*} p<0.05\right)$. a. mRNA expression of IL-6. b. mRNA expression of type I collagen. c. mRNA expression of type III collagen. $\mathbf{d}$. mRNA expression of tenomodulin. e. mRNA expression of MMP-9. f. mRNA expression of TIMP-1. g. mRNA expression of TIMP-2 
maximize the signal in the Achilles tendon. Picrosirius Red stains type I collagen yellow and type III collagen green. For semiquantitative evaluation of collagen expression, we measured the chromaticity of yellow for type I collagen ( $n=8$ in each group).

\section{Statistical analysis}

The data is presented as mean \pm standard deviation (SD) of independent experiments. The Excel statistical software package (Ekuseru-Toukei 2015; Social Survey Research Information Co., Ltd., Tokyo, Japan) was used to perform all the statistical analyses of the recorded data. The data were expressed as the $\mathrm{n}$-fold difference from the SAMR1 group. For a comparison of the two groups, two-way analysis of variance (ANOVA) was performed. Post hoc analysis was performed by Fisher's protected least significant difference test. A value of $p<0.05$ was considered significant.

\section{Results}

In both SAMP6 and SAMR1 mice, collagenase injection triggered tendon inflammation resulting in increased expression of IL-6 and MMP-9 compared with the contralateral (control) limb. Expression of IL-6 and MMP-9 was significantly higher in the SAMP6 mice compared with the controls (Fig. 1a and e). In the control groups, expression of type I collagen (a tendon matrix marker) was significantly lower in the SAMP6 mice compared with the SAMR1 mice. Type I collagen expression in the collagenase-injected group was significantly lower than the control group both in SAMR1 and SAMP6 mice (Fig. 1b). Type III collagen was increased in both SAMP6 and SAMR1 mice after collagenase injection (Fig. 1c). On the other hand, tenomodulin expression was decreased after collagenase injection in the SAMP6 group, although a statistically significant decrease was not seen in the SAMR1 group (Fig. 1d). In control tendons, expression of TIMP-1 and TIMP-2 was statistically higher in SAMP6 mice compared with SAMR1 mice. Collagenase injection decreased TIMP-1 and TIMP-2 expression in both SAMR1 and the SAMP6 mice (Fig. If and g). There was no significant difference in TIMP-1 and TIMP-2 expression between the collagenase-injected SAMR1 and the SAMP6 mice. The measured value are shown in Table 1.

Picrosirius Red staining showed strong expression of type I collagen in the SAMR1 control group. On the other hand, expression of type I collagen was decreased in SAMP6 mice, especially after collagenase injection (Fig. 2). Quantitative analysis showed that type I collagen expression decreased following collagenase injection especially in SAMP6 mice (Fig. 3, Table 2).

\section{Discussion}

Tendinitis is defined as the inflammation of a tendon and is the first stage of tendinosis, which is a degeneration of
Table 1 mRNA expressions in the Achilles tendons of SAMR1 and SAMP6

(a) IL-6

$\begin{array}{lllll} & \text { SAMR1 } & & \text { SAMP6 } & \\ & \text { control } & \text { collagenase } & \text { control } & \text { collagenase } \\ \text { value } & 1.00 & 2.59 & 0.99 & 10.12 \\ \text { SD } & 0.21 & 0.25 & 0.13 & 0.79\end{array}$

(b) Type I collagen

\begin{tabular}{lllll} 
& SAMR1 & & SAMP6 \\
& control & collagenase & control & collagenase \\
value & 1.00 & 0.01 & 0.29 & 0.02 \\
SD & 0.05 & 0.00 & 0.02 & 0.01 \\
(c) Type III collagen & & & \\
\multicolumn{5}{r}{} \\
& SAMR1 & & SAMP6 & \\
value & control & collagenase & control & collagenase \\
SD & 1.00 & 9.35 & 1.19 & 6.11 \\
(d) & 0.02 & 1.63 & 1.03 & 1.25
\end{tabular}

(d) Tenomodulin

$\begin{array}{lllll} & \text { SAMR1 } & & \text { SAMP6 } & \\ & \text { control } & \text { collagenase } & \text { control } & \text { collagenase } \\ \text { value } & 1.00 & 0.83 & 0.54 & 0.43 \\ \text { SD } & 0.32 & 0.55 & 0.16 & 0.00\end{array}$

(e) MMP-9

$\begin{array}{lllll} & \text { SAMR1 } & & \text { SAMP6 } & \\ & \text { control } & \text { collagenase } & \text { control } & \text { collagenase } \\ \text { value } & 1.00 & 1.14 & 0.99 & 2.37 \\ \text { SD } & 0.32 & 0.25 & 0.05 & 0.58 \\ \text { (f) TIMP-1 } & & & & \\ & \text { SAMR1 } & & \text { SAMP6 } & \\ & \text { control } & \text { collagenase } & \text { control } & \text { collagenase } \\ \text { value } & 1.00 & 0.07 & 1.31 & 0.06 \\ \text { SD } & 0.15 & 0.04 & 0.01 & 0.02\end{array}$

(g) TIMP-2

\begin{tabular}{lllll} 
& SAMR1 & & SAMP6 & \\
& control & collagenase & control & collagenase \\
value & 1.00 & 0.21 & 7.01 & 0.90 \\
SD & 1.29 & 0.09 & 2.01 & 0.35 \\
\hline
\end{tabular}

Table 2 Expression of type I collagen was semiquantitatively analyzed by the chromaticity of yellow in Fig. 2

\begin{tabular}{|c|c|c|c|c|}
\hline & \multicolumn{2}{|l|}{ SAMR1 } & \multicolumn{2}{|l|}{ SAMP6 } \\
\hline & control & collagenase & control & collagenase \\
\hline value & 1.00 & 0.49 & 0.43 & 0.03 \\
\hline SD & 0.29 & 0.15 & 0.10 & 0.02 \\
\hline
\end{tabular}




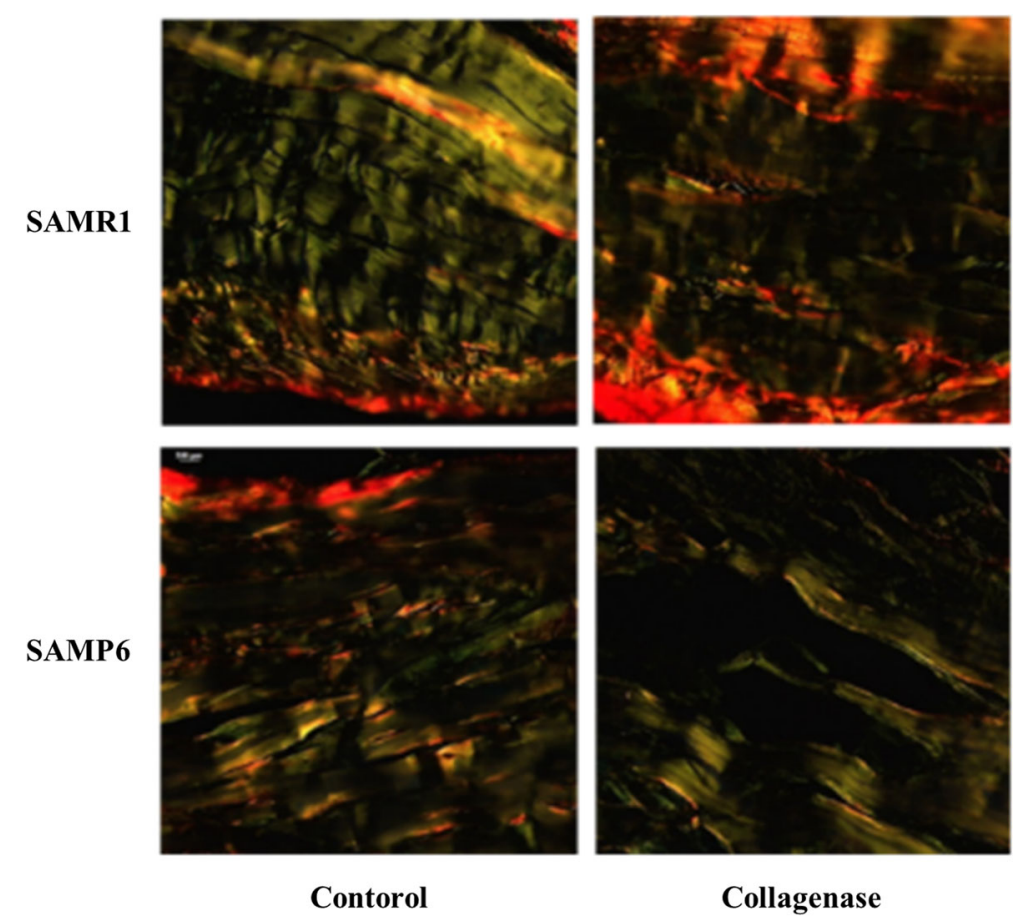

Fig. 2 Collagen arrangement in the Achilles tendon stained using Picrosirius Red. Yellow represent type I collagen and green represents type III collagen

the tendon's collagen in response to chronic overuse or aging. IL-6 is an important reactive cytokine expressed during inflammation [14]. Expression of some IL-6 family members is upregulated in the pathological tendon [15]. The physiological role of IL- 6 has mostly been studied in

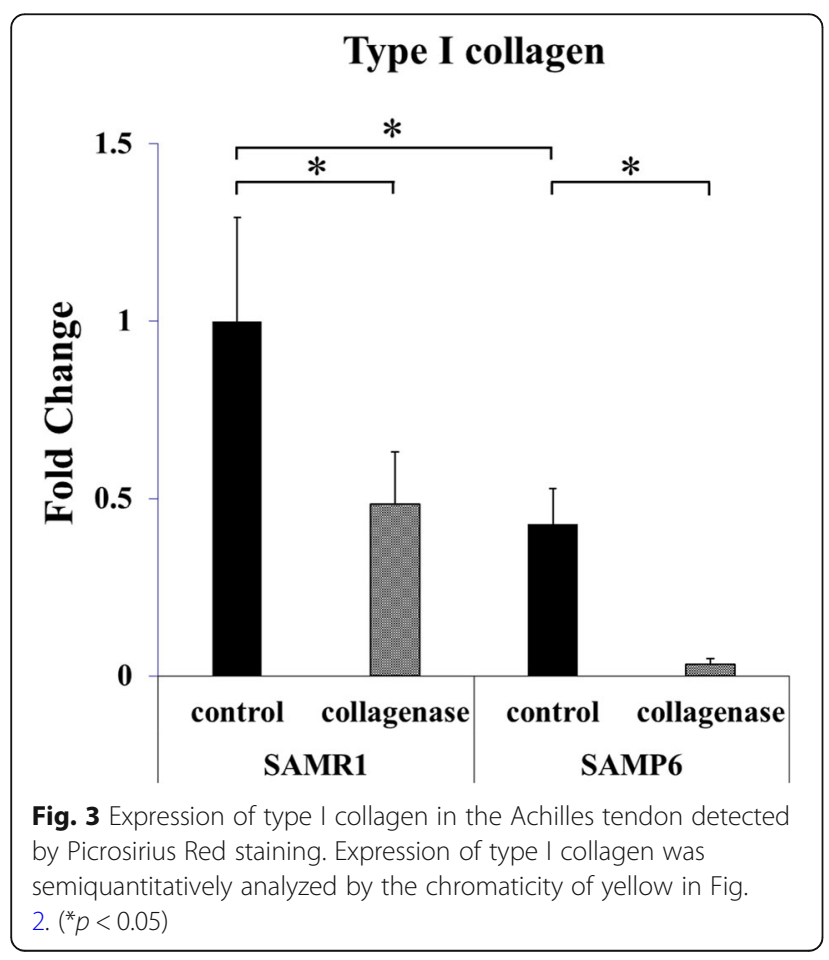

the context of the acute phase response, although there is growing evidence that IL- 6 also plays a central role in the pathogenesis of chronic disease [16]. Collagen metabolism has also been shown to be influenced by IL-6 [17]. In the present study, IL-6 was analyzed to evaluate the degree of collagenase-induced inflammation in tendons. There is no significant difference in IL-6 mRNA expression between SAMR1 and SAMP6 in control groups (SAMR1, $1.0 \pm$ 0.21 ; SAMP6, $0.99 \pm 0.13$ ). These results resemble the previous report that there is no difference between the young rats and aged rats in the serum IL-6 level [18]. Therefore, the baseline levels of tendon inflammation in these aging mice (SAMP6) and control mice (SAMR1) have no difference. Gene and protein expression of IL-6 increased in acute human RC and Achilles tendon tear [15, 19, 20], which continued until two weeks post-surgical repair [21]. On the other hand, its expression after acute tendon injury in the aged mouse is not known. In the present study, both SAMR1 and SAMP6 mouse showed upregulation of IL-6 after collagenase injection.

Compared with collagenase-injected SAMR1 mice, there was a strong upregulation of IL-6 in SAMP6 mice. This shows that more severe inflammation was induced by collagenase injection in the Achilles tendons of the aged mouse group.

Tenomodulin is a mature marker for tendon and ligament lineage cells. Its absence leads to an inferior tendon repair process, resulting in adipocyte accumulation and fibrovascular scar formation during early tendon healing 
[22]. The ability of tendon-derived stem/progenitor cells to differentiate into tenocytes also diminishes with age $[23,24]$. Expression of tenomodulin was lower in aged TSPCs compared with young cells [23]. But, there are few previous reports that compare tenomodulin expression of aged with young in early phase from tendon injury.

In the present study, tenomodulin expression was lower in SAMP6 mice and was decreased by collagenase injection. This result indicates that tendon repair ability is decreased in aged tendons under inflammatory condition compared with younger tendons.

Matrix turnover involves the synthesis and degradation of matrix components and is important for the maintenance and repair of tendons. Decreased collagen turnover and altered gene expression of the extracellular matrix was reported in aged tendon [25]. In normal tendons, approximately $90 \%$ of the collagen is type I, whereas type III collagen is upregulated during inflammation [26]. A study using human Achilles tendon showed that levels of type III collagen mRNA were significantly higher in tendons with chronic pain or spontaneous rupture compared with normal tendons [27]. Approximately $90 \%$ of the collagen in normal tendons is type I. In tendinopathic and ruptured Achilles tendons; there is a reduction in the proportion of type I collagen, and a significant increase in the amount of type III collagen. [28] Microtrauma within the tendon may heal by the production of type III collagen, which is an abnormal healing response. [28] In the present study, the expression of type III collagen in collagenase injected groups is lower in SAMP6 than SAMR1. This may indicate that SAMP6 has lower potential to express type III collagen during its healing process after tendon injury.

MMPs play a key role in regulating matrix remodeling and are considered responsible for the degradation of collagens and proteoglycans $[29,30]$. The present study revealed that the expression of MMP-9 was higher in the tendons of aged mice compared with those of younger mice. A similar age-dependent increase in MMP-2 or MMP-9 activity was also reported in skin, heart, articular cartilage, and even plasma [31-34].

TIMPs are tissue-specific, endogenous inhibitors of MMPs. All known MMPs are inhibited by all TIMPs; however, the efficacy of MMP inhibition varies [35]. For example, TIMP-1 strongly inhibits many MMPs except for membrane-type MMPs, including MMP-14, 15, 16, 19, and 24 [35]. There is considerable evidence supporting an inhibitory effect of TIMP-2 on extracellular matrix proteolysis in several tissues [36, 37]. Our study showed that the expressions of TIMP-1 and TIMP-2 are increased in SAMP6 tendons compared to SAMR1 in control group. Collagenase injection decreased these expressions both in SAMR1 and SAMP6. The balance of MMPs and TIMPs is important for tendon matrix turnover. In the present study, an imbalance of these tendon remodeling factors was observed in the aged inflammatory tendon. We believe that under the inflammatory conditions of the aged tendon, the imbalance of MMPs and TIMPs negatively affected tendon matrix turnover, leading to altered expression of type I and type III collagen, representing a weaker remodeling ability.

There are several limitations to this study. The SAMP6 mouse model is not a normal aging model. Although it is not a transgenic mouse, some strains show amyloidosis, immunodeficiency, renal atrophy, and learning disabilities. SAMP6 mice spontaneously develop osteoporosis or sarcopenia early in life and are used in musculoskeletal research. In the future, a similar study using a normal strain could confirm the present results. Biomechanical evaluation of the Achilles tendon of the aged mouse was not performed in the present study due to limited animal numbers. Further studies are required to determine the relevance of aging on the mechanical properties of the tendon.

\section{Conclusion}

The aged tendon showed increased inflammation and decreased tendon remodeling. Therefore, aging may have a suppressive effect on the tendon healing process. The results indicate that aging may lead to dysfunction of the tendon healing process after acute tendon injury.

\begin{abstract}
Abbreviations
cDNA: Complementary deoxyribonucleic acid; GAPDH: Glyceraldehyde 3phosphate dehydrogenase; IL-6: Interleukin-6; MMP: Matrix metalloproteinase; OCT: Optimal cutting temperature; PCR: Polymerase chain reaction; RNA: Ribonucleic acid; SAM: Senescence-accelerated mouse; SAMP: Senescence-accelerated mouse prone; SAMR: Senescence-accelerated mouse resistant; SD: Standard deviation; TIMP: Tissue inhibitors of metalloproteinase; TSPC: Tendon stem/progenitor cell
\end{abstract}

\section{Acknowledgements \\ The authors would like to give a special thanks to Ms. MYasuda, Ms. KTanaka and Ms. MNagata (Department of Orthopaedic Surgery, Kobe University Graduate School of Medicine) for their excellent technical assistance.}

Funding

No funding was obtained for this study.

Availability of data and materials

The datasets supporting the conclusions of this article are included within the article and could be provided through direct contact to the first author (YUeda) on reasonable request.

\begin{abstract}
Authors' contributions
$\mathrm{YU}, \mathrm{Al}$ and $\mathrm{YM}$ made substantial contributions to the conception, design and drafting of this manuscript. YU performed collagenase injection and real-time PCR. TKa performed histological examination. YU, FT, TKa, TKu and KY perfomed data analysis and interpretation. Al, YM, TKo and RK conceived of the study, and participated in its design and coordination. All authors read and approved the final manuscript.
\end{abstract}

Ethics approval and consent to participate

Our IRB (Institutional Animal Care and Use Committee At kusunoki and

Myodani Campus Kobe University) provided the approval for our study and the approval informations are follows. (Permission Number: P140610-R1). All animal procedures were performed under the approval and guidance of our IRB. 


\section{Consent for publication}

Not applicable.

\section{Competing interests}

The authors declare that they have no competing interests.

\section{Publisher's Note}

Springer Nature remains neutral with regard to jurisdictional claims in published maps and institutional affiliations.

Received: 25 May 2018 Accepted: 4 March 2019

Published online: 21 March 2019

\section{References}

1. Steinbacher P, Tauber M, Kogler S, Stoiber W, Resch H, Sanger AM. Effects of rotator cuff ruptures on the cellular and intracellular composition of the human supraspinatus muscle. Tissue Cell. 2010;42(1):37-41.

2. Robinson PM, Wilson J, Dalal S, Parker RA, Norburn P, Roy BR. Rotator cuff repair in patients over 70 years of age: early outcomes and risk factors associated with re-tear. Bone Joint J. 2013;95-b(2):199-205.

3. Matough FA, Budin SB, Hamid ZA, Alwahaibi N, Mohamed J. The role of oxidative stress and antioxidants in diabetic complications. Sultan Qaboos Univ Med J. 2012;12(1):5-18.

4. Visse R, Nagase H. Matrix metalloproteinases and tissue inhibitors of metalloproteinases: structure, function, and biochemistry. Circ Res. 2003; 92(8):827-39.

5. Yu TY, Pang JH, Wu KP, Chen MJ, Chen CH, Tsai WC. Aging is associated with increased activities of matrix metalloproteinase-2 and -9 in tenocytes. BMC Musculoskelet Disord. 2013;14:2

6. Dudhia J, Scott CM, Draper ER, Heinegard D, Pitsillides AA, Smith RK. Aging enhances a mechanically-induced reduction in tendon strength by an active process involving matrix metalloproteinase activity. Aging Cell. 2007;6(4):547-56

7. Takeda T, Hosokawa M, Higuchi K. Senescence-accelerated mouse (SAM): a novel murine model of senescence. Exp Gerontol. 1997;32(1-2):105-9.

8. Chen X, Li L, Guo J, Zhang L, Yuan Y, Chen B, Sun Z, Xu J, Zou J. Treadmill running exercise prevents senile osteoporosis and upregulates the Wnt signaling pathway in SAMP6 mice. Oncotarget. 2016;7(44):71072-86.

9. Chen H, Zhou X, Emura S, Shoumura S. Site-specific bone loss in senescence-accelerated mouse (SAMP6): a murine model for senile osteoporosis. Exp Gerontol. 2009;44(12):792-8.

10. Chen H, Yao XF, Emura S, Shoumura S. Morphological changes of skeletal muscle, tendon and periosteum in the senescence-accelerated mouse (SAMP6): a murine model for senile osteoporosis. Tissue Cell. 2006;38(5):325-35.

11. Frizziero A, Vittadini F, Gasparre G, Masiero S. Impact of oestrogen deficiency and aging on tendon: concise review. Muscles Ligaments Tendons J. 2014;4(3):324-8.

12. Tsai YP, Chang CW, Lee JS, Liang Jl, Hsieh TH, Yeh ML, Sze Cl. Direct radiofrequency application improves pain and gait in collagenase-induced acute achilles tendon injury. Evid Based Complement Alternat Med : eCAM. 2013;2013:402692.

13. Lui PP, Chan LS, Fu SC, Chan KM. Expression of sensory neuropeptides in tendon is associated with failed healing and activity-related tendon pain in collagenase-induced tendon injury. Am J Sports Med. 2010;38(4):757-64.

14. Hodge DR, Hurt EM, Farrar WL. The role of IL-6 and STAT3 in inflammation and cancer. Eur J Cancer (Oxford, England : 1990). 2005;41(16):2502-12.

15. Legerlotz K, Jones ER, Screen HR, Riley GP. Increased expression of IL-6 family members in tendon pathology. Rheumatology (Oxford). 2012; 51(7):1161-5.

16. Bauer J, Bauer TM, Kalb T, Taga T, Lengyel G, Hirano T, Kishimoto T, Acs G, Mayer L, Gerok W. Regulation of interleukin 6 receptor expression in human monocytes and monocyte-derived macrophages. Comparison with the expression in human hepatocytes. J Exp Med. 1989;170(5):1537-49.

17. Rowan $A D$, Koshy PJ, Shingleton WD, Degnan BA, Heath JK, Vernallis AB, Spaull JR, Life PF, Hudson K, Cawston TE. Synergistic effects of glycoprotein 130 binding cytokines in combination with interleukin-1 on cartilage collagen breakdown. Arthritis Rheum. 2001;44(7):1620-32.

18. Xin DL, Harris MY, Wade CK, Amin M, Barr AE, Barbe MF. Aging enhances serum cytokine response but not task-induced grip strength declines in a rat model of work-related musculoskeletal disorders. BMC Musculoskelet Disord. 2011;12:63.
19. Millar NL, Wei AQ, Molloy TJ, Bonar F, Murrell GA. Cytokines and apoptosis in supraspinatus tendinopathy. J Bone Joint Surg. 2009;91(3):417-24.

20. Dakin SG, Martinez FO, Yapp C, Wells G, Oppermann U, Dean BJ, Smith RD, Wheway K, Watkins B, Roche L, et al. Inflammation activation and resolution in human tendon disease. Sci Transl Med. 2015;7(311):311ra173.

21. Ackermann PW, Domeij-Arverud E, Leclerc P, Amoudrouz P, Nader GA. Antiinflammatory cytokine profile in early human tendon repair. Knee Surg Sports Traumatol Arthrosc. 2013;21(8):1801-6.

22. Lin D, Alberton P, Caceres MD, Volkmer E, Schieker M, Docheva D. Tenomodulin is essential for prevention of adipocyte accumulation and fibrovascular scar formation during early tendon healing. Cell Death Dis. 2017:8(10):e3116.

23. Zhou Z, Akinbiyi T, Xu L, Ramcharan M, Leong DJ, Ros SJ, Colvin AC, Schaffler $M B$, Majeska RJ, Flatow EL, et al. Tendon-derived stem/progenitor cell aging: defective self-renewal and altered fate. Aging Cell. 2010;9(5):911-5.

24. Murchison ND, Price BA, Conner DA, Keene DR, Olson EN, Tabin CJ, Schweitzer R. Regulation of tendon differentiation by scleraxis distinguishes force-transmitting tendons from muscle-anchoring tendons. Development. 2007:134(14):2697-708.

25. Kjaer M, Magnusson P, Krogsgaard M, Boysen Moller J, Olesen J, Heinemeier K, Hansen M, Haraldsson B, Koskinen S, Esmarck B, et al. Extracellular matrix adaptation of tendon and skeletal muscle to exercise. J Anat. 2006;208(4):445-50.

26. Amiel D, Frank C, Harwood F, Fronek J, Akeson W. Tendons and ligaments: a morphological and biochemical comparison. J Orthop Res. 1984;1(3):257-65.

27. Ireland D, Harrall R, Curry V, Holloway G, Hackney R, Hazleman B, Riley G. Multiple changes in gene expression in chronic human Achilles tendinopathy. Matrix Biol. 2001;20(3):159-69.

28. Maffulli N, Ewen SW, Waterston SW, Reaper J, Barrass V. Tenocytes from ruptured and tendinopathic achilles tendons produce greater quantities of type III collagen than tenocytes from normal achilles tendons. An in vitro model of human tendon healing. Am J Sports Med. 2000;28(4):499-505.

29. Riley G. Tendinopathy--from basic science to treatment. Nat Clin Pract Rheumatol. 2008:4(2):82-9.

30. Sharma P, Maffulli N. Biology of tendon injury: healing, modeling and remodeling. J Musculoskelet Neuronal Interact. 2006;6(2):181-90.

31. Lindsey ML, Goshorn DK, Squires CE, Escobar GP, Hendrick JW, Mingoia JT, Sweterlitsch SE, Spinale FG. Age-dependent changes in myocardial matrix metalloproteinase/tissue inhibitor of metalloproteinase profiles and fibroblast function. Cardiovasc Res. 2005;66(2):410-9.

32. Mine S, Fortunel NO, Pageon H, Asselineau D. Aging alters functionally human dermal papillary fibroblasts but not reticular fibroblasts: a new view of skin morphogenesis and aging. PLoS One. 2008;3(12):e4066.

33. Gepstein A, Shapiro S, Arbel G, Lahat N, Livne E. Expression of matrix metalloproteinases in articular cartilage of temporomandibular and knee joints of mice during growth, maturation, and aging. Arthritis Rheum. 2002; 46(12):3240-50.

34. Bonnema DD, Webb CS, Pennington WR, Stroud RE, Leonardi AE, Clark LL, McClure CD, Finklea L, Spinale FG, Zile MR. Effects of age on plasma matrix metalloproteinases (MMPs) and tissue inhibitor of metalloproteinases (TIMPs). J Card Fail. 2007;13(7):530-40.

35. Arpino V, Brock M, Gill SE. The role of TIMPs in regulation of extracellular matrix proteolysis. Matrix Biol. 2015;44(46):247-54.

36. Lieu S, Hansen E, Dedini R, Behonick D, Werb Z, Miclau T, Marcucio R, Colnot C. Impaired remodeling phase of fracture repair in the absence of matrix metalloproteinase-2. Dis Model Mech. 2011;4(2):203-11.

37. Ratajczak-Wielgomas K, Gosk J, Rabczynski J, Augoff K, Podhorska-Okolow M, Gamian A, Rutowski R. Expression of MMP-2, TIMP-2, TGF-beta1, and decorin in Dupuytren's contracture. Connect Tissue Res. 2012;53(6):469-77.

Ready to submit your research? Choose BMC and benefit from:

- fast, convenient online submission

- thorough peer review by experienced researchers in your field

- rapid publication on acceptance

- support for research data, including large and complex data types

- gold Open Access which fosters wider collaboration and increased citations

- maximum visibility for your research: over $100 \mathrm{M}$ website views per year

At BMC, research is always in progress.

Learn more biomedcentral.com/submissions 